\title{
GESTÃO AMBIENTAL EM ESCOLAS DE NEGÓCIOS: MAPEANDO O ESTADO DA ARTE
}

\author{
ENVIRONMENTAL MANAGEMENT IN BUSINESS SCHOOLS: MAPPING THE STATE OF \\ THE ART
}

Recebido em 14.06.2014. Aprovado em 03.12.2014

Avaliado pelo sistema double blind review

DOI: http://dx.doi.org/10.12712/rpca.v8i4.461

\author{
Charbel José Chiappetta Jabbour \\ prof.charbel@gmail.com \\ UNESP - Universidade Estadual Paulista "Júlio de Mesquita Filho" - Araçatuba - SP - Brasil
}

\section{Resumo}

Após as diretrizes da Organização das Nações Unidas, que instituíram a Década da Educação para o Ensino de Desenvolvimento Sustentável (2005-2014) e o lançamento dos Principles for a Responsible Management Education (PRME), a pressão para que as Escolas de Negócios/Gestão incorporem a gestão ambiental em suas atividades essenciais (ensino, pesquisa, extensão e gestão universitária) se intensificaram. Em contrapartida, no Brasil, essa discussão é ainda embrionária, e, em alguns casos, as Escolas de Negócios parecem estar em descompasso com a gestão ambiental praticada pelas empresas classe-mundial do setor industrial. Por isso, neste artigo é prospectado e sistematizado o estado-da-arte sobre a inclusão da temática ambiental nas atividades das Escolas de Negócios, mapeando-se o território das principais obras do tema. Os principais resultados indicam que no estado-da-arte vigora: uma pujante liderança de pesquisadores estadunidenses e de outros países desenvolvidos na temática; um evidente reducionismo analítico das pesquisas, ao enfocarem principalmente a dimensão "ensino", não abordando uma perspectiva sistêmica que englobe a gestão ambiental no conjunto de atividades típicas das Escolas de Negócios; uma significativa predominância de estudos teóricos sobre o tema e uma consequente carência de estudos teórico-empíricos, principalmente de estudo de múltiplos casos.

Palavras-chave: Gestão ambiental. Escolas de Negócios. Sustentabilidade. Estado da arte.

\begin{abstract}
Following the guidelines of the United Nations, which established the Decade of Education for Sustainable Development (2005-2014) and the Principles for Responsible Management Education (PRME), the pressure on business schools for incorporating environmental management in their core activities (teaching, research, extension and university management) have intensified. In contrast, in Brazil, this discussion is still embryonic, and in some cases, the Business Schools seem to be in latter than the environmental management practiced by the world-class companies in the industrial sector. Therefore, this article prospected and systematized the state of the art on the inclusion of environmental management issues in the activities of Business Schools, by mapping the territory of the main academic works in this subject. The main results indicate that the state of the art is represented by: a vibrant leadership
\end{abstract}


of U.S. researchers and others developed countries, a clear analytical reductionism of research, mainly by focusing on the dimension "teaching" does not addressing a systemic perspective that encompasses environmental management in the range of typical activities of Business Schools, a significant predominance of theoretical studies on the subject and a consequent lack of empirical studies, mainly based on multiple cases.

Keywords: Environmental Management. Business Schools. State of the art.

\section{Introdução}

A ação organizacional pode ser considerada responsável pelo avanço da deterioração ambiental atualmente testemunhada; também pode e deve assumir papel essencial na alteração desse cenário, fomentando as melhorias ambientais almejadas por todos os setores da sociedade. Dessa forma, as organizações devem incorporar a temática ambiental em suas atividades essenciais (BOIRAL, 2006; WOOLVERTON e DIMITRI, 2010; SARKIS, GONZÁLEZ-TORRE e ADENSO-DIAZ, 2010; JACOBS, SINGHAL e SUBRAMANIAN, 2010).

A incorporação da temática ambiental nas organizações vem recebendo diversas denominações, tais como "gestão ambiental", "gestão da sustentabilidade ambiental", "gestão ambientalmente responsável", "gestão verde", entre muitas outras. Com efeito, esses termos somente fazem sentido se transformados em resultados práticos, quando os dirigentes organizacionais - aqui chamados de administradores - possuírem conhecimentos, habilidades e atitudes pró-gestão ambiental. Tal argumentação possui profundas implicações para as Escolas de Negócios (conhecidas na literatura internacional como Business Schools, B-School ou B-S) (WALCK, 2009; PEOPLES, 2009; JABBOUR, 2010).

Uma das principais implicações é que as Escolas de Negócios constituem o lócus primário e fundamental de formação de futuros gestores organizacionais - indivíduos que devem liderar as organizações na árdua jornada rumo a uma sociedade ambientalmente sustentável (WHEELWE, ZOHAR e HART, 2005). Schwartz, Kassem e Ludwig (1991) perceberam a relevância das Escolas de Negócios na construção de uma sociedade mais sustentável ainda na década de 1990. Segundo os autores, essas Escolas constituem o berço formativo de parcela significativa de líderes empresariais, e por isso se encontram estrategicamente posicionadas para produzir impactos negativos ou positivos na formação ética desses líderes, impactos esses que podem influenciar o rumo da sociedade por meio de um "efeito dominó".

Em um artigo clássico, Hasan (1993) argumenta que as Escolas de Administração ao redor do mundo possuem a obrigação de apresentar os desafios ambientais da humanidade e das organizações aos seus alunos, de forma clara e instigante. Para esse autor, já na década de 1990, a janela de oportunidade para que as Escolas de Negócios incorporassem a dimensão ambiental em suas atividades encontrava-se aberta, entretanto, extinguindo-se gradativamente. Nesse sentido, Walk (2009), em um apelo à comunidade de Gestão, afirma que se os estudantes - os futuros dirigentes de inúmeras organizações - não compreenderem precisamente as ameaças e oportunidades geradas pelos desafios ambientais às organizações e à sociedade, não haverá incentivo para qualquer tipo de mudança.

Conforme afirmação contida no documento oficial da Organização das Nações Unidas para fomento a uma educação gerencial mais responsável (PRME-ONU, 2010), entende-se que as iniciativas das Escolas de Negócios - incluindo-se aquelas de cunho ambiental - devem servir como exemplo e incentivo para os estudantes dessas Escolas. Entretanto, o campo de pesquisa sobre a incorporação da temática ambiental nas Escolas de Negócios se revela como escasso. 
Por isso, diversas iniciativas acadêmicas emergiram para fomentar a produção de conhecimentos sobre a incorporação da gestão ambiental na área de Administração e Gestão, dentre as quais se destacam:

- Escolha do tema "Green Management Matter" como eixo central daquele que é o mais prestigioso congresso mundial da área de Administração, o Academy Of Management Annual Meeting, edição 2009 (AOM, 2009);

- Call for Papers e publicação de um Special Issue sobre "Sustainability in Management Education", pelo prestigioso Academy Of Management Learning \& Education Journal, em 2010 (STARIK et al., 2010), periódico indexado ao Journal Citation Reports da Thompson;

- Call for Papers e publicação de um Special Issue sobre "Greening across the management curriculum", publicado no Journal of Management Education, em 2006 (RUSINKO e SAMA, 2006);

- Call for Papers e publicação de um Special Issue sobre "Teaching about the Natural environment in management education: new directions and approaches", publicado no Journal of Management Education, em 2003 (EGRI e ROGERS, 2003).

Entretanto, pelo seu caráter emergente, pouco ainda se sabe sobre os contornos e panorama do "território" da produção científica sobre a gestão ambiental em Escolas de Negócios. Conseqüentemente, o objetivo deste artigo é mapear o estado-da-arte sobre o greening das atividades de Escolas de Negócios, enfatizando: (a) a descrição dessas obras, com foco nos principais autores, objetivos das pesquisas, abordagem metodológica e país de origem da autoria; (b) uma sistematização das principais características do conjunto de obras analisadas; (c) uma agenda de pesquisa futuras.

\section{Fundamentos Conceituais}

\section{Gestão ambiental em Escolas de Negócios}

Nas últimas décadas, as Escolas de Negócios têm sido um dos principais vetores do rápido crescimento do ensino superior no mundo (THOMAS e LI, 2009), tornando-se um expressivo componente do ensino superior mundial, mas surpreendentemente essas Escolas vêm recebendo pouca atenção dos pesquisadores, sendo alvo pouco freqüente de investigações cujo objetivo seja aperfeiçoar a ação dessas organizações (STARKEY e TIRATSO0, 2007).

A pujança das Escolas de Negócios não as torna imunes às críticas. Como observam Jakobsen, Ims e Gronhaug (2005), muitos dos escândalos e crises da esfera organizacional acabam gerando sérias críticas às Escolas de Administração. Nesse sentido, as Escolas de Negócios tendem a ser consideradas responsáveis pela imagem muitas vezes negativas que as organizações gozam perante a opinião pública. Swanson (2004) cita os resultados de uma pesquisa conduzida pelo Wall Street Journal, indicativos de que quase $80 \%$ dos entrevistados acreditam que a imagem das organizações norte-americanas "não é boa" ou "é terrível", o que provavelmente deve gerar conseqüências para as Escolas formadoras dos administradores que lideram essas organizações.

A imagem perante a opinião pública é apenas um dos desafios para as Escolas de Administração. Para Cornuel (2007), a "era dourada" das Escolas de Negócios e a pujança de seu movimento estão sendo afrontados por: 
- Dificuldade para a atração e retenção de jovens professores de Administração;

- Massificação do ensino superior;

- Globalização do ensino, com a responsabilidade de fomentar a internacionalização de seus conhecimentos;

- Alterações curriculares;

- Formação de líderes globalmente responsáveis.

Esse último aspecto citado por Cornuel (2007), mas não menos desafiador, é o alvo desta pesquisa. Nas palavras de Hasan (1993), o dilema ambiental a que se submetem as Escolas de Negócios é articular, desenvolver e oferecer educação ambiental para administradores como uma forma efetiva para a criação e manutenção de uma sociedade sustentável. Mas teriam os gestores do passado, os atuais e os vindouros um cabedal de conhecimentos útil ao processo de decisão ambientalmente adequado? (HASAN, 1993). Qualquer uma das respostas possíveis a este questionamento, positiva, negativa ou intermediária, gera indubitáveis implicações para as Escolas de Administração, lócus típico de formação dos gestores organizacionais (WALCK, 2009). Para Rohweder (2004), a gestão ambiental praticada rotineiramente nas organizações nada mais será do que reflexo sobre como as Escolas de Negócios se posicionam em relação ao tema.

Esses questionamentos não são tão recentes. Já na década de 1980, Thompson (1985) indicou a inevitabilidade do movimento ambiental bater às portas das Escolas de Administração. A mesma questão levou Hoffman (1999) a concluir que as Escolas de Negócios dos Estados Unidos não estavam incorporando o conhecimento ambiental em suas atividades de ensino. Ainda segundo este autor, os conhecimentos em gestão ambiental ensinados aos estudantes são muitas vezes vistos como secundários, quando comparados a outras disciplinas clássicas de Administração. De fato, esse posicionamento não reflete o atual avanço dos conhecimentos disponíveis sobre os positivos impactos das atividades de gestão ambiental na competitividade das organizações (por exemplo, MOLINA-AZORIN et al., 2009).

As Escolas de Negócios devem tornar claro aos seus estudantes que eles podem ser bons gestores ao mesmo tempo em que ponderam aspectos ambientais em seus processos de tomada de decisão e atividades diárias (HOFFMAN, 1999). Objetivos de gestão ambiental são consistentes com objetivos gerenciais e outros indicadores de desempenho das organizações, principalmente porque estratégias de gestão ambiental podem gerar oportunidades do tipo ganha-ganha, nas quais são melhorados indicadores ambientais e de negócios de uma dada organização. A relação positiva entre gestão ambiental e desempenho organizacional, por meio de co-benefícios sinérgicos entre essas variáveis, que ficou conhecida como Hipótese win-win ou Hipótese de Porter e Linde (1995) foi confirmada em pesquisas recentes (DARNALL, HENRIQUES e SADORSKY, 2008; IRALDO, TESTA e FREY, 2009; CROWE e BRENNAN 2007; VACHON e KLASSEN 2008; SROUFE 2003; YANG et., 2010; GONZÁLEZ-BENITO e GONZÁLEZBENITO 2005; SROUFE, 2003)

Alguns argumentos dos pesquisadores dedicados à temática da incorporação da gestão ambiental nas Escolas de Negócios revelam a urgência de se analisar como essas Escolas estão agindo em relação à gestão ambiental:

- Como afirmaram ainda na década de 1990, Smith, Hart e McCloskey (1994), "se quisermos alterações [pró-gestão ambiental] nos pressupostos administrativos, nós teremos que 
garantir mudanças significativas na forma como os administradores são atualmente educados";

- Uma vez que a gestão ambiental está sendo incorporada no centro das organizações, ela deve também ser incorporada nas Escolas de Negócios (HOFFMAN, 1999);Em muitos casos, as Escolas de Negócios encontram-se extremamente atrasadas sobre as possibilidades e desafios da gestão ambiental realizada em empresas líderes. Por isso, as Escolas de Negócios precisam, com urgência, resgatar o tempo perdido e assumir a posição de liderança que não deveriam ter perdido na construção de organizações ambientalmente sustentáveis (BARNES e FERRY, 1992).

- Para que as transformações rumo a uma sociedade com organizações mais sustentáveis aconteçam é importante que novos conceitos sejam apresentados a todos os Administradores, de todos os níveis hierárquicos das organizações (GARDINER e LACY, 2005).

- Se nossos estudantes não entenderem o impacto de suas ações no meio ambiente nas atividades em que eles operam, não haverá incentivo para qualquer mudança (WALK, 2009)

Ainda que a plausibilidade dos argumentos expostos seja evidente, assim, como é clara a percepção de que as Escolas de Negócios devem acompanhar as rápidas transformações que vêm ocorrendo na sociedade (ONZOÑO e CARMONA, 2007), Rohweder (2004) assevera que até o momento há evidências de que muitas Escolas de Negócios não estão respondendo adequadamente ao imperativo ambiental. A dificuldade de inclusão de temas ambientais nas Escolas de Negócios foi investigada por este autor. Segundo ele, duas são as principais barreiras para a efetiva inserção da gestão ambiental nas atividades das Escolas de Negócios (ROHWEDER, 2004):

- Abordagem pessoal e centrada no docente. A inclusão da gestão ambiental nas atividades das Escolas de Negócios tende a depender do esforço pessoal de um dado professor que se interessa pelo tema. Dessa forma, há um "efeito individual e personalista" da inclusão da gestão ambiental nas Escolas de Administração; em outras palavras, a inclusão da gestão ambiental ocorre geralmente por meio de uma abordagem centrada em poucos docentes auto-motivados para a causa ambiental;

- Comportamento e pensamento territorial. Identificou-se que a maior parte dos docentes que não pertencem à área de gestão ambiental a tratam como tema secundário, passando a defender seu próprio "território" de conhecimentos, dificultando uma abordagem transversal da gestão ambiental, isto é, sua inclusão no conjunto de disciplinas de um curso de Administração.

Até o momento, pesquisadores como Gardiner e Lacy (2005) acreditam que a maior parte das Escolas de Negócios parece estar falhando na missão de transformar a formação dos Administradores em uma ação organizacional mais sustentável. Outros pesquisadores, como Barnes e Ferry (1992), acreditam que, em muitos casos, as Escolas de Negócios estejam anos atrasadas em termos de gestão ambiental quando comparadas com os conhecimentos e práticas ambientais encontrados nas mais prestigiosas empresas do mundo.

\section{Posicionamentos ambientais das Escolas de Negócios}

Diante do exposto, parece haver um descompasso nas Escolas de Negócios, instituições que deveriam estar, de fato, liderando o movimento pró-gestão ambiental. Os resultados desse "elo 
perdido ambiental" podem ser expressos na reflexão apresentada por Peoples (2009). Esse autor, baseado em sua experiência de mais de 30 anos trabalhando com projetos sobre gestão ambiental e apresentando-os a administradores, formulou um modelo explicativo (Figura 1) sobre como a falta de conhecimentos sobre gestão ambiental pode comprometer a inclusão da gestão ambiental no dia-a-dia das organizações.

Para Peoples (2009), projetos organizacionais pró-gestão ambiental, com potencial melhoria para a organização e para a sociedade, quando apresentados para administradores formados por Escolas de Negócios que não incluem a gestão ambiental em suas atividades são sempre alvo de falta de informação e desconfiança, fruto de eventuais confusões e dúvidas. Gestores com baixo nível de conhecimentos sobre gestão ambiental tendem a não se comprometer com iniciativas de gestão ambiental e tendem a não tomar decisões sobre tema. Não há ação, não há progresso e geralmente esses gestores solicitam que a temática ambiental seja desconsiderada. Esse processo pode resultar em frustração, ineficiência organizacional e retrabalho para os proponentes de ações organizacionais pró-gestão ambiental.

Uma das principais alternativas para a quebra do ciclo viciado apresentado por Peoples (2009) é a ação pró-ativa das Escolas de Negócios. Cohen (1990, p.31), delineia diretrizes para que as Escolas de Negócios cumpram essa missão:

- Sensibilizar os estudantes de administração para a ampla gama de questões ambientais com a qual eles deverão lidar como futuros gestores;

- Desenvolver competências analíticas e de solução de problemas incluindo a questão ambiental no processo de tomada de decisão;

- Promover educação ambiental para os executivos já formados;

- Catalisar pesquisas sobre a relação entre gestão ambiental e as outras áreas funcionais de uma organização, como, por exemplo, marketing, recursos humanos, produção e finanças.

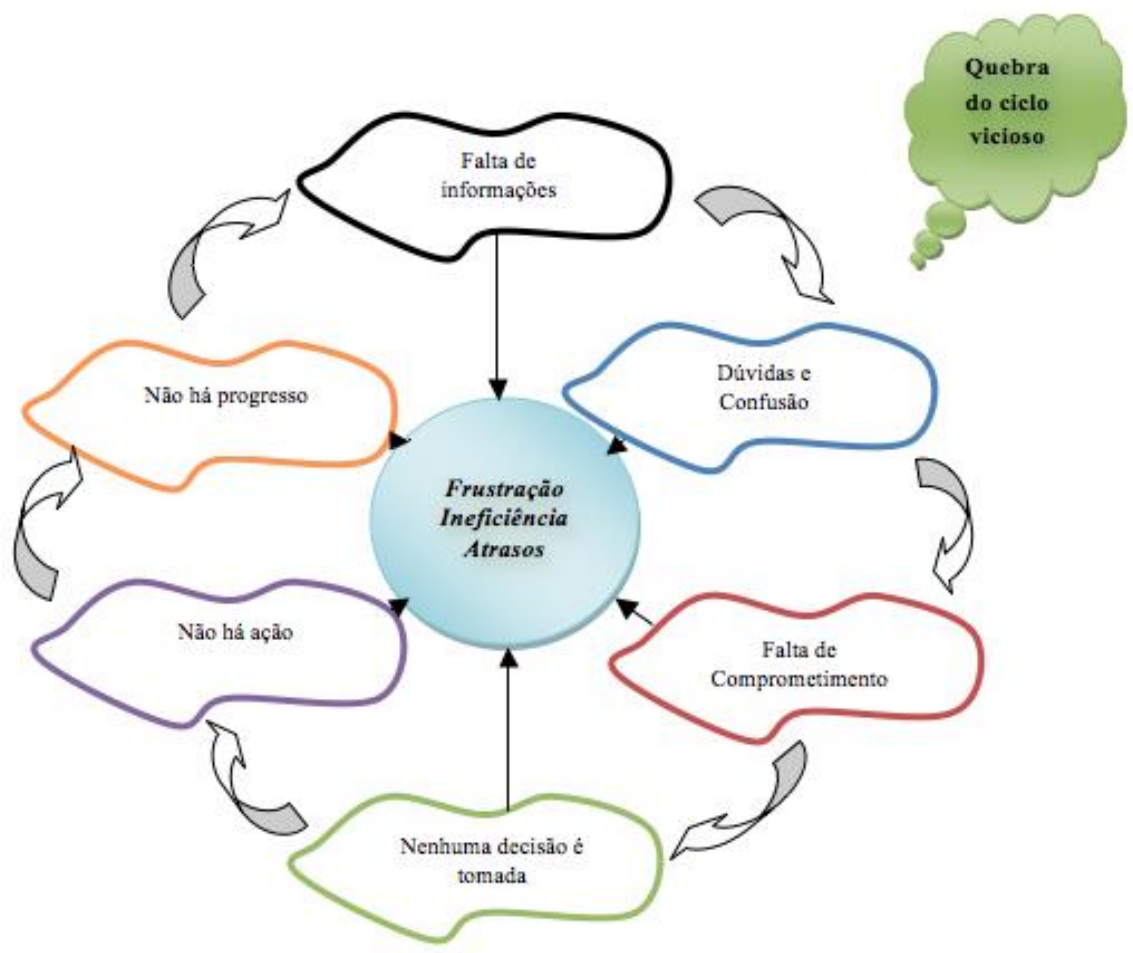

Figura 1 - Diagrama da dúvida em relação à gestão ambiental.

Fonte: Adaptado de Peoples (2009). 
Entretanto, nem todas as Escolas de Negócios tratam o tema da gestão ambiental com o mesmo nível de maturidade, assim como evidenciado na literatura sobre estágios evolutivos da gestão ambiental empresarial (JABBOUR, 2010).

Com base nas propostas de Gardiner e Lacy (2005), é possível identificar três posicionamentos típicos das Escolas de Negócios frente o desafio de incorporar a temática da responsabilidade corporativa, a qual, por definição, compreende assuntos próprios da gestão ambiental (Figura 2). Em um nível inferior de comprometimento com a temática da responsabilidade corporativa, as Escolas de Negócios tendem a ignorar o debate, na esperança de que ele não passe de um modismo, continuando a ensinar Administração como sempre o fizeram. Em um estágio intermediário, as Escolas de Negócios podem apenas responder a estímulos dos stakeholders, não correndo os riscos, nem aproveitando as oportunidades de uma postura antecipatória e pró-ativa. Em um nível mais avançado de comprometimento, as Escolas de Negócios podem exercer um papel de liderança, desenvolvendo, por meio de suas atividades essenciais, ensino, pesquisa, extensão e gestão universitária, ações que impulsionem a fronteira de conhecimento do tema.

As Escolas de Negócios encontram na literatura especializada justificativas para se posicionarem no estágio "liderar" descrito acima. São de Gardiner e Lacy (2005 p.176) os resultados de uma pesquisa com stakeholders de Escolas de Negócios, que teve a finalidade de verificar o nível de demanda desses indivíduos em formação gerencial mais responsável. Segundo os autores, a pesquisa "identificou uma clara demanda por novos modelos de negócio e habilidades administrativas para ajudar as empresas a responder ao triple bottom line dos negócios: econômico, social e ambiental". Os resultados da pesquisa podem ser assim descritos:

- Há uma clara demanda por parte dos dirigentes organizacionais e estudantes por pesquisa, educação e especialização em temas relacionados a uma ação mais responsável das organizações perante a sociedade;

- 0 ensino sobre temas relacionados a uma ação mais responsável das organizações na sociedade ainda está longe do "mainstream" do currículo dos cursos de administração, o que pode gerar vantagem competitiva para as Escolas pioneiras do movimento de incorporação da gestão ambiental em suas atividades. 


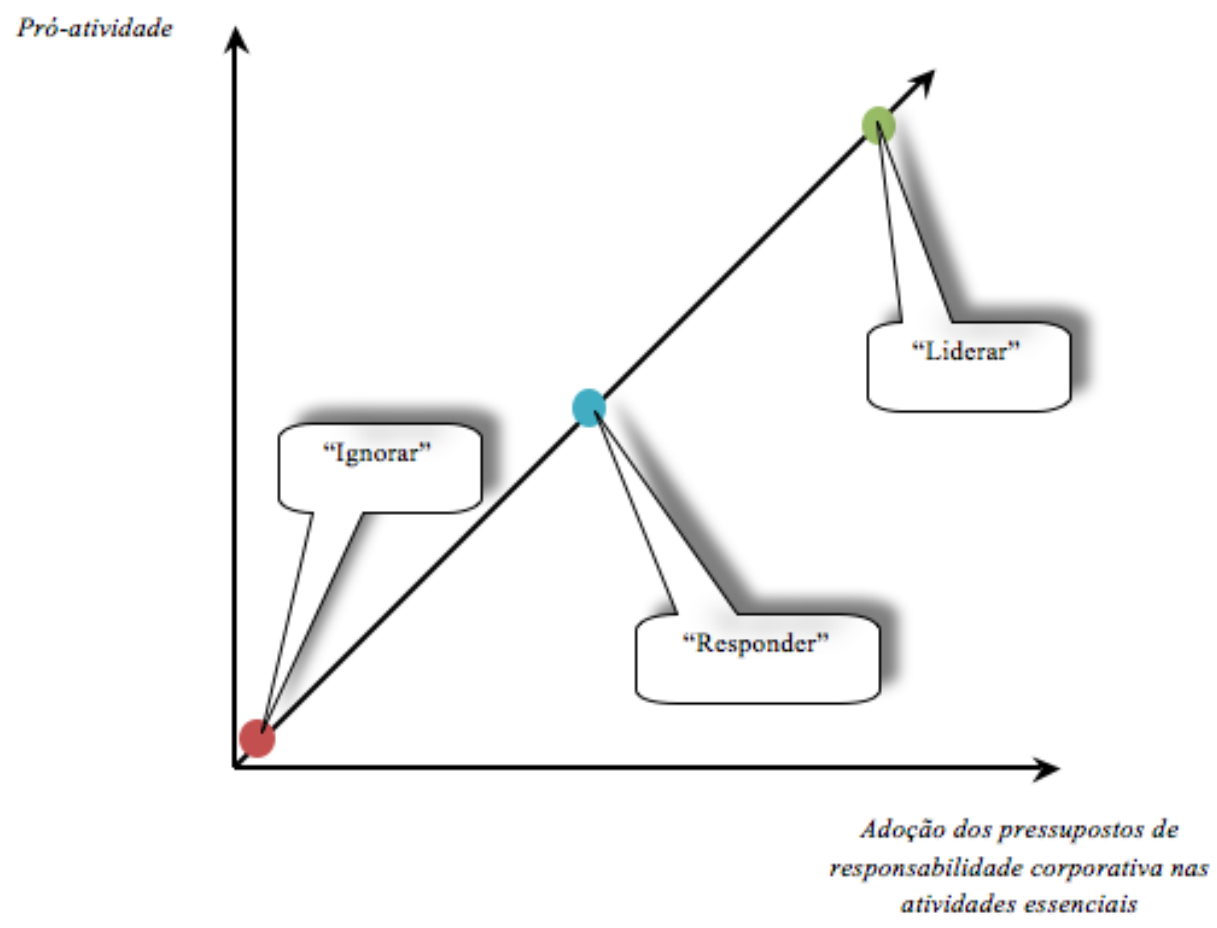

Figura 2 - Possibilidades de posicionamentos das Escolas de Negócios perante a temática da Responsabilidade Corporativa.

Fonte: Adaptado de Gardiner e Lacy (2005 p.176).

O estágio de liderança em relação à gestão ambiental proposto por Gardiner e Lacy (2005) pode ser analisado por meio de um arcabouço conceitual mais amplo, proposto brilhantemente por Boyle (2004), no qual a inclusão da gestão ambiental nas Escolas de Negócios é elemento fundamental do processo chamado por Boyle (2004) de "Cidadania das Escolas de Administração". Segundo a autora, somente quando as Escolas de Negócios se transformarem em agentes-cidadãos elas possuirão legitimidade perante a sociedade e status nas universidades a que pertencem. Segundo Boyle (2004), a cidadania das Escolas de Negócios diz respeito às atividades desenvolvidas por essas organizações com o intuito primário de promover avanço no bem-estar da sociedade e contribuir com o bem-estar público, incluindo-se aí, portanto, a preocupação com a gestão ambiental. A autora, ainda que tenha desenvolvido um trabalho eminentemente teórico, é a pioneira no debate sobre a relevância de uma transformação em todas as atividades essenciais das Escolas de Negócios: ensino, pesquisa, extensão e gestão universitária, com o intuito de incorporar temas de cidadania organizacional, dentre os quais se destaca a gestão ambiental.

Boyle (2004) argumenta que a transformação pretendida nas atividades de ensino, pesquisa, extensão e gestão universitária são factíveis, podem ser verificadas na realidade por meio de variáveis mensuráveis e que sua adoção engendra múltiplos benefícios:

- Podem ser auferidos benefícios individuais, para alunos, docentes e funcionários;

- É possível a obtenção de benefícios institucionais;

- São garantidos benefícios sociais.

No Quadro 1 são expostos, para cada atividade essencial de Escolas de Negócios mais cidadãs, estratégias de ação e implementação transformadoras, bem como os conseqüentes benefícios 
que podem ser auferidos.

\begin{tabular}{|c|c|c|c|c|}
\hline $\begin{array}{l}\text { Atividades } \\
\text { Essenciais }\end{array}$ & Operacionalização & $\begin{array}{l}\text { Benefícios } \\
\text { Individuais }\end{array}$ & $\begin{array}{l}\text { Benefícios para a } \\
\text { Escola de } \\
\text { Administração }\end{array}$ & Benefícios Sociais \\
\hline Ensino & $\begin{array}{l}\text { Cidadania aprendida por } \\
\text { meio de disciplinas, } \\
\text { áreas de concentração, } \\
\text { estágios, projetos e } \\
\text { premiações }\end{array}$ & $\begin{array}{l}\text { - Os estudantes } \\
\text { ganham } \\
\text { - Conhecimento e } \\
\text { experiência; } \\
\text { oportunidades de } \\
\text { ascensão na carreira; } \\
\text { satisfação pessoal e } \\
\text { visibilidade pública }\end{array}$ & $\begin{array}{l}\text { - Escolas ganham } \\
\text { - Habilidade para } \\
\text { atingir sua missão; } \\
\text { atendimento aos } \\
\text { requisitos de } \\
\text { qualidade dos órgãos } \\
\text { certificadores; } \\
\text { legitimidade por } \\
\text { formar estudantes } \\
\text { mais responsáveis }\end{array}$ & $\begin{array}{l}\text { - Sociedade ganha } \\
\text { pessoas com maior } \\
\text { comprometimento } \\
\text { com a } \\
\text { sustentabilidade; } \\
\text { - Dirigentes } \\
\text { organizacionais } \\
\text { ganham com } \\
\text { funcionários mais } \\
\text { responsáveis }\end{array}$ \\
\hline Pesquisa & $\begin{array}{l}\text { Conhecimento sobre } \\
\text { cidadania corporativa } \\
\text { desenvolvido e } \\
\text { disseminado por meio } \\
\text { de publicações, } \\
\text { conferências e eventos }\end{array}$ & $\begin{array}{l}\text { - Os docentes ganham } \\
\text { - Conhecimento } \\
\text { teórico e prático; } \\
\text { conhecimento para } \\
\text { ser trocado com } \\
\text { colegas acadêmicos; } \\
\text { oportunidade de } \\
\text { avanço na carreira } \\
\text { acadêmica }\end{array}$ & $\begin{array}{l}\text { - Reconhecimento } \\
\text { público, patentes, } \\
\text { publicações } \\
\text { qualificadas; } \\
\text { recursos para } \\
\text { fomento à pesquisa; } \\
\text { - Aumento da } \\
\text { legitimidade para } \\
\text { continuar o projeto } \\
\text { de formação de } \\
\text { Administradores } \\
\end{array}$ & $\begin{array}{l}\text { - Sociedade ganha } \\
\text { novos } \\
\text { conhecimentos que } \\
\text { podem incentivar } \\
\text { indivíduos e } \\
\text { organizações em } \\
\text { um ciclo virtuoso }\end{array}$ \\
\hline Extensão & $\begin{array}{l}\text { Cidadania colocada em } \\
\text { prática por meio de } \\
\text { parcerias com o setor } \\
\text { privado e público, trocas } \\
\text { de experiências com a } \\
\text { comunidade e outras } \\
\text { atividades }\end{array}$ & $\begin{array}{l}\text { - Comunidade e } \\
\text { empresas locais } \\
\text { ganham com o } \\
\text { aperfeiçoamento de } \\
\text { seus negócios; } \\
\text { - Docentes e } \\
\text { funcionários ganham } \\
\text { melhores condições } \\
\text { de trabalho } \\
\text { (equipamentos, } \\
\text { instalações); } \\
\text { - Alunos ganham por } \\
\text { aprender sobre } \\
\text { exemplos práticos }\end{array}$ & $\begin{array}{l}\text { - Legitimidade via } \\
\text { projetos } \\
\text { colaborativos que } \\
\text { integram diferentes } \\
\text { organizações, de } \\
\text { diferentes setores da } \\
\text { sociedade; }\end{array}$ & $\begin{array}{l}\text { - Melhoria da } \\
\text { qualidade de vida da } \\
\text { comunidade } \\
\text { - Maiores } \\
\text { oportunidades de } \\
\text { obtenção de renda } \\
\text { para indivíduos da } \\
\text { comunidade } \\
\text { - "Empowerment" da } \\
\text { comunidade para } \\
\text { lidar com problemas } \\
\text { sócio-ambientais }\end{array}$ \\
\hline $\begin{array}{c}\text { Gestão } \\
\text { universitária }\end{array}$ & $\begin{array}{l}\text { Cidadania aplicada ao } \\
\text { próprio processo } \\
\text { administrativo. Envolve } \\
\text { o desenvolvimento e a } \\
\text { disseminação de uma } \\
\text { política organizacional } \\
\text { sócio-ambiental }\end{array}$ & $\begin{array}{l}\text { - Docentes, } \\
\text { funcionários e } \\
\text { estudantes ganham } \\
\text { com práticas de } \\
\text { gestão socialmente } \\
\text { adequadas e com a } \\
\text { adoção de práticas de } \\
\text { gestão ambiental, } \\
\text { como reciclagem, } \\
\text { construções verdes, } \\
\text { etc. }\end{array}$ & $\begin{array}{l}\text { - Reputação } \\
\text { - Redução de custos } \\
\text { operacionais por } \\
\text { meio de eco- } \\
\text { eficiência } \\
\text { - Avanço em práticas } \\
\text { de gestão social que } \\
\text { melhoram a } \\
\text { qualidade de vida dos } \\
\text { funcionários }\end{array}$ & $\begin{array}{l}\text { - Redução dos } \\
\text { impactos } \\
\text { ambientais gerados; } \\
\text { - Transferência de } \\
\text { conhecimentos } \\
\text { sobre gestão de } \\
\text { organizações } \\
\text { educacionais para } \\
\text { outras Escolas de } \\
\text { Administração }\end{array}$ \\
\hline
\end{tabular}

Quadro 1 - Inclusão de aspectos de cidadania empresarial nas Escolas de Negócios: atividades essenciais, operacionalização e benefícios

Fonte: Adaptado de Boyle (2004, p.59).

Nesse contexto, é digna de nota uma experiência recente, ainda pouco conhecida por muitos dirigentes de Escolas de Administração, mas consideravelmente promissora, cuja missão é fomentar uma educação mais responsável de Administradores ao redor do mundo, incluindo-se 
nesse movimento a preocupação com a formação em gestão ambiental. Trata-se da parceria entre a Organização das Nações Unidas e líderes empresariais consubstanciada no documento “Principles for a Responsible Management Education" (PRME-ONU, 2010).

O papel do "Principles for a Responsible Management Education" (PRME) é incorporar a sustentabilidade e a responsabilidade social na missão central e nas atividades das escolas de administração. O PRME representa um esforço conjunto entre a ONU e Escolas de Negócios para fomentar uma educação em Administração que considere a responsabilidade social e a sustentabilidade (FORRAY e LEIGH, 2010).

Qualquer Escola de Administração do mundo pode aderir ao PRME, recebendo em contra partida uma declaração de Instituição signatária emitida pela ONU. As Escolas de Negócios participantes devem declarar publicamente seu comprometimento com os seis princípios do PRME, além de enviar à ONU um relatório anual contendo avanços e desafios enfrentados pela Escola de Administração nesse processo. Centenas de Escolas de Negócios de todo o mundo já aderiram ao PRME.

No Quadro 2 são apresentados os seis princípios que norteiam o PRME, o propósito de cada um desses princípios, bem como seu significado para a edificação de uma educação administrativa mais responsável nas Escolas de Negócios signatárias.

\begin{tabular}{|c|c|c|}
\hline Princípios & $\begin{array}{c}\text { Propósito } \\
\text { do princípio }\end{array}$ & Definição \\
\hline Princípio 1 & Proposta & $\begin{array}{c}\text { "We will develop the capabilities of students to be future generators of } \\
\text { sustainable value for business and society at large and to work for an } \\
\text { inclusive and sustainable global economy." }\end{array}$ \\
\hline Princípio 2 & Valores & $\begin{array}{c}\text { "We will incorporate into our academic activities and curricula the values } \\
\text { of global social responsibility as portrayed in international initiatives such } \\
\text { as the United Nations Global Compact." }\end{array}$ \\
\hline Princípio 3 & Métodos & $\begin{array}{c}\text { "We will create educational frameworks, materials, processes and } \\
\text { environments that enable effective learning experiences for responsible } \\
\text { leadership." }\end{array}$ \\
\hline Princípio 4 & Pesquisas & $\begin{array}{l}\text { "We will engage in conceptual and empirical research that advances our } \\
\text { understanding about the role, dynamics, and impact of corporations in the } \\
\text { creation of sustainable social, environmental and economic value." }\end{array}$ \\
\hline Princípio 5 & Parcerias & $\begin{array}{c}\text { "We will interact with managers of business corporations to extend our } \\
\text { knowledge of their challenges in meeting social and environmental } \\
\text { responsibilities and to explore jointly effective approaches to meeting } \\
\text { these challenges." }\end{array}$ \\
\hline Princípio 6 & Diálogos & $\begin{array}{c}\text { “We will facilitate and support dialog and debate among educators, } \\
\text { business, government, consumers, media, civil society organizations and } \\
\text { other interested groups and stakeholders on critical issues related to } \\
\text { global social responsibility and sustainability.” }\end{array}$ \\
\hline
\end{tabular}

Quadro 1 - PRME: Princípios, propósitos e definições

Fonte: PRME-ONU (2010).

É perceptível que o PRME mostra uma clara tendência: as Escolas de Negócios devem incorporar temas para uma educação administrativa, e em particular sobre gestão ambiental, considerando de forma cabal suas atividades essenciais. Segundo Jabbour (2010) essa perspectiva exige uma abordagem sistêmica, onde além de se considerar a incorporação da 
gestão ambiental na totalidade de atividades desenvolvidas pelas Escolas de Negócios, faz-se necessário entender como essas atividades encontram-se interligadas e como influenciam o "greening" das Escolas de Negócios.

\section{Método de Pesquisa}

Nesta pesquisa, considera-se estado-da-arte o conjunto de resultados de pesquisa sobre a inclusão da gestão ambiental em Escolas de Negócios que tenha sido comunicado para a comunidade científica internacional e que esteja indexado e disponível nas bases de dados científicas internacionais de elevado prestígio e impacto, proporcionando avanço significativo na fronteira do conhecimento. Na tentativa de sistematização do estado-da-arte sobre a inclusão da gestão ambiental nas atividades das Escolas de Negócios, adotaram-se os seguintes procedimentos:

- Foram prospectados artigos científicos e outros tipos de referências nas bases científicas internacionais, notadamente aquelas que disponibilizam artigos redigidos na língua inglesa. 0 estado-da-arte representa o nível máximo de avanço de um campo de conhecimento no mundo e por isso remete a comunicados de pesquisas em inglês e de impacto universal;

- Iniciou-se a prospecção de referências nas mais prestigiosas bases de indexação: ISI/Web of Science e Scopus;

- Considerando-se que nem todos os periódicos de interesse estejam indexados às bases científicas mencionadas, realizou-se uma busca detalhada no banco de dados de cada uma das principais editoras internacionais de artigos científicos: (1) Elsevier, por meio da base ScienceDirect; (2) Emerald, com sua base Emerald Insight; (3) John Wiley, por meio da base InderScience; (4) Taylor \& Francis, através da base InformaWorld; (5) Sage; e (6) Springer;

- Por fim, foram visitados e minuciosamente analisados os bancos de artigos de periódicos dedicados ao tema da educação gerencial (como, por exemplo, o Journal of Management Education) e direcionados à temática do ensino de gestão ambiental (principalmente o International Journal of Sustainability in Higher Education).

A busca dos artigos foi realizada por meio da inserção, no campo de busca das bases de dados citadas, da combinação ou uso isolado dos seguintes termos: "environmental management", "business schools", "green business schools", "green management schools", "management schools", "greening of business schools", "greening of management schools", "business schools and the environment", entre outros termos. Embora tenha se revelado uma quantidade relativamente expressiva de artigos de natureza mais ampla e genérica sobre a inclusão da gestão ambiental em Instituições de Ensino Superior, apenas 20 artigos com implicações para a inclusão da gestão ambiental nas Escolas de Negócios. Essas obras foram analisadas, sistematizadas, classificadas segundo seu grau de contribuição à inclusão da gestão ambiental nas atividades essenciais das Escolas de Negócios (ensino, pesquisa, extensão e administração), e isoladas segundo a nacionalidade e origem institucional dos seus principais autores (primeiro autor).

\section{Resultados}

\section{Descrição das obras componentes do estado-da-arte do tema}

O Quadro 3 apresenta os principais resultados da prospecção e revisão da literatura sobre o "greening" das Escolas de Negócios empreendidas com escopo internacional, conforme as variáveis: (a) autoria da pesquisa; (b) contribuição; (c) atividade(s) da Escola de Negócios focadas; (d) abordagem metodológica; (e) método de pesquisa; e (f) origem institucional da 
primeira autoria. 


\begin{tabular}{|c|c|c|c|c|c|}
\hline Pesquisa & $\begin{array}{c}\text { Contribuição ao } \\
\text { estado-da-arte }\end{array}$ & Foco & Abordagem & Método & $\begin{array}{c}\text { Origem } \\
\text { institucional } \\
\end{array}$ \\
\hline $\begin{array}{l}\text { Southwick } \\
\text { (1970) }\end{array}$ & $\begin{array}{l}\text { Relata o pioneiro esforço } \\
\text { da empresa } \\
\text { estadunidense } \\
\text { Westinghouse em se } \\
\text { associar com } \\
\text { universidades para a } \\
\text { criação da } \\
\text { "Westinghouse's } \\
\text { Environmental School: } \\
\text { Combining Business } \\
\text { with Ecology", com a } \\
\text { finalidade de oferecer } \\
\text { educação ambiental para } \\
\text { os seus principais } \\
\text { executivos. A experiência } \\
\text { considerada exitosa e } \\
\text { ocorreu na década de } \\
\text { 1970. }\end{array}$ & Ensino & $\begin{array}{l}\text { Teórico- } \\
\text { Empírica }\end{array}$ & Estudo de Caso & $\begin{array}{c}\text { EUA, Colorado } \\
\text { State } \\
\text { University }\end{array}$ \\
\hline $\begin{array}{l}\text { Thompson } \\
\text { (1985) }\end{array}$ & $\begin{array}{l}\text { Argumenta, de forma } \\
\text { visionária, que as } \\
\text { Escolas de Negócios } \\
\text { devem se engajar no } \\
\text { movimento pró-gestão } \\
\text { ambiental. }\end{array}$ & Ensino & Teórico & Revisão bibliográfica & EUA/ * \\
\hline $\begin{array}{l}\text { Barnes e } \\
\text { Ferry (1992) }\end{array}$ & $\begin{array}{l}\text { Critica as Escolas de } \\
\text { Negócios por estarem } \\
\text { atrasadas em termos de } \\
\text { conhecimento sobre } \\
\text { gestão ambiental quando } \\
\text { comparadas a algumas } \\
\text { empresas como 3M e } \\
\text { DuPont. Traça } \\
\text { estratégias para o } \\
\text { desenvolvimento de } \\
\text { disciplina sobre o tema. }\end{array}$ & Ensino & $\begin{array}{l}\text { Teórico- } \\
\text { Empírica }\end{array}$ & Revisão bibliográfica & $\begin{array}{c}\text { EUA, Indiana } \\
\text { University }\end{array}$ \\
\hline $\begin{array}{l}\text { Hasan } \\
(1993)\end{array}$ & $\begin{array}{l}\text { Destaca a relevância da } \\
\text { incorporação da gestão } \\
\text { ambiental nas Escolas de } \\
\text { Administração, bem } \\
\text { como o papel decisivo } \\
\text { dessas Escolas na } \\
\text { criação de uma } \\
\text { sociedade mais } \\
\text { sustentável. } \\
\end{array}$ & Ensino & Teórica & Revisão bibliográfica & $\begin{array}{l}\text { EUA, Eastern } \\
\text { Washington } \\
\text { University }\end{array}$ \\
\hline $\begin{array}{l}\text { Smith, Hart e } \\
\text { McCloskey } \\
\text { (1994) }\end{array}$ & $\begin{array}{l}\text { Chamam a atenção para } \\
\text { a importância das } \\
\text { Escolas de Negócios para } \\
\text { a inclusão da gestão } \\
\text { ambiental no ensino de } \\
\text { Administração, como } \\
\text { mecanismo para a } \\
\text { mitigação dos impactos } \\
\text { ambientais } \\
\text { proporcionados pelas } \\
\text { organizações. }\end{array}$ & Ensino & Teórica & Revisão bibliográfica & $\begin{array}{l}\text { Reino Unido, } \\
\text { Liverpool John } \\
\text { Moores } \\
\text { University, } \\
\text { Business } \\
\text { School }\end{array}$ \\
\hline $\begin{array}{l}\text { Hoffman } \\
\text { (1999) }\end{array}$ & $\begin{array}{l}\text { Desenvolve argumentos } \\
\text { a favor da incorporação } \\
\text { da gestão ambiental em }\end{array}$ & Ensino & Teórica & Revisão bibliográfica & $\begin{array}{l}\text { EUA, Boston } \\
\text { University } \\
\text { School of } \\
\end{array}$ \\
\hline
\end{tabular}




\begin{tabular}{|c|c|c|c|c|c|}
\hline & $\begin{array}{l}\text { Escolas de } \\
\text { Administração, } \\
\text { principalmente para os } \\
\text { cursos de MBA. }\end{array}$ & & & & Management \\
\hline $\begin{array}{l}\text { Cordano, } \\
\text { Ellis e } \\
\text { Scherer } \\
(2003)\end{array}$ & $\begin{array}{l}\text { Compara a sensibilidade } \\
\text { ambiental de estudantes } \\
\text { de Escola de } \\
\text { Administração antes e } \\
\text { depois do contato com } \\
\text { material instrucional } \\
\text { sobre gestão ambiental } \\
\text { em uma disciplina. } \\
\text { Confirmam que o } \\
\text { contato dos estudantes } \\
\text { com o material } \\
\text { instrucional potencializa } \\
\text { a sensibilidade } \\
\text { ambiental desses alunos. }\end{array}$ & Ensino & $\begin{array}{l}\text { Teórico- } \\
\text { Empírica }\end{array}$ & $\begin{array}{c}\text { Quantitativo - } \\
\text { Survey }\end{array}$ & $\begin{array}{l}\text { EUA, Ithaca } \\
\text { College }\end{array}$ \\
\hline $\begin{array}{l}\text { Pesonen } \\
(2003)\end{array}$ & $\begin{array}{l}\text { Relata os meandros da } \\
\text { criação, manutenção e } \\
\text { melhoria contínua de um } \\
\text { curso de mestrado com } \\
\text { foco em sustentabilidade } \\
\text { ambiental em uma } \\
\text { Escola de Administração } \\
\text { da Finlândia. }\end{array}$ & Ensino & $\begin{array}{l}\text { Teórico- } \\
\text { Empírica }\end{array}$ & Estudo de Caso & $\begin{array}{l}\text { Finlândia, } \\
\text { University of } \\
\text { Jyväskyla }\end{array}$ \\
\hline $\begin{array}{l}\text { Kearins e } \\
\text { Springett } \\
\text { (2003) }\end{array}$ & $\begin{array}{l}\text { Ressaltam a relevância } \\
\text { de incorporação da } \\
\text { sustentabilidade } \\
\text { ambiental no currículo } \\
\text { de Administração, por } \\
\text { meio do } \\
\text { desenvolvimento de uma } \\
\text { abordagem reflexiva e } \\
\text { crítica. Apresentam } \\
\text { exemplos de exercícios } \\
\text { para uso em sala de aula } \\
\text { com esse propósito. }\end{array}$ & Ensino & Teórico & Revisão bibliográfica & $\begin{array}{l}\text { Nova } \\
\text { Zelândia, } \\
\text { University of } \\
\text { Waikato }\end{array}$ \\
\hline $\begin{array}{l}\text { Coopey } \\
(2003)\end{array}$ & $\begin{array}{l}\text { Desenvolveu uma } \\
\text { pesquisa com base em } \\
\text { dados secundários } \\
\text { fornecidos por Escolas } \\
\text { de Negócios do Reino } \\
\text { Unido, com a finalidade } \\
\text { de analisar o nível de } \\
\text { incorporação da } \\
\text { temática ambiental em } \\
\text { algumas atividades das } \\
\text { Escolas de } \\
\text { Administração. Conclui } \\
\text { que a gestão ambiental é } \\
\text { ainda tema periférico } \\
\text { quando comparado às } \\
\text { áreas clássicas de } \\
\text { Administração. }\end{array}$ & $\begin{array}{l}\text { Ensino/ } \\
\text { Pesquisa }\end{array}$ & $\begin{array}{l}\text { Teórico- } \\
\text { Empírica }\end{array}$ & $\begin{array}{c}\text { Revisão } \\
\text { bibliográfica/ análise } \\
\text { de dados } \\
\text { secundários }\end{array}$ & $\begin{array}{c}\text { Reino Unido, } \\
\text { Lancaster } \\
\text { University }\end{array}$ \\
\hline Boyle (2004) & $\begin{array}{l}\text { Desenvolve pioneiro } \\
\text { trabalho sobre "Escolas } \\
\text { de Negócios Cidadãs" e } \\
\text { sobre as conseqüentes } \\
\text { alterações nas atividades }\end{array}$ & $\begin{array}{c}\text { Ensino/ } \\
\text { Pesquisa/ } \\
\text { Extensão/ } \\
\text { Administração }\end{array}$ & Teórica & Revisão bibliográfica & $\begin{array}{c}\text { EUA, Clark } \\
\text { University's } \\
\text { Graduate } \\
\text { School of } \\
\text { Management }\end{array}$ \\
\hline
\end{tabular}




\begin{tabular}{|c|c|c|c|c|c|}
\hline & $\begin{array}{l}\text { essenciais dessas } \\
\text { Escolas: ensino, } \\
\text { pesquisa, extensão e } \\
\text { administração. }\end{array}$ & & & & \\
\hline $\begin{array}{l}\text { Rohweder } \\
\text { (2004) }\end{array}$ & $\begin{array}{l}\text { Sistematiza a } \\
\text { experiência de } \\
\text { incorporação da gestão } \\
\text { ambiental no plano de } \\
\text { ensino de Escolas de } \\
\text { Negócios da Finlândia. } \\
\text { Apresenta dois } \\
\text { principais desafios para } \\
\text { essa incorporação: } \\
\text { "abordagem centrada no } \\
\text { docente" e "demarcação } \\
\text { territorial". }\end{array}$ & Ensino & $\begin{array}{l}\text { Teórico- } \\
\text { Empírica }\end{array}$ & $\begin{array}{l}\text { Estudo de Múltiplos } \\
\text { Casos }\end{array}$ & $\begin{array}{l}\text { Finlândia, } \\
\text { Helsinki } \\
\text { Business } \\
\text { Polytechnic }\end{array}$ \\
\hline $\begin{array}{l}\text { Gardiner e } \\
\text { Lacy (2005) }\end{array}$ & $\begin{array}{l}\text { Apresenta os resultados } \\
\text { de uma pesquisa } \\
\text { realizada com alunos, } \\
\text { acadêmicos e práticos } \\
\text { sobre os desafios e } \\
\text { oportunidades para as } \\
\text { Escolas de Negócios } \\
\text { frente o tema } \\
\text { "responsabilidade } \\
\text { corporativa", que inclui a } \\
\text { temática da gestão } \\
\text { ambiental. } \\
\text { Adicionalmente, os } \\
\text { autores apresentam } \\
\text { tendências para as } \\
\text { Escolas de } \\
\text { Administração. }\end{array}$ & Ensino & $\begin{array}{l}\text { Teórico- } \\
\text { Empírica }\end{array}$ & $\begin{array}{l}\text { Quantitativo - } \\
\text { Survey }\end{array}$ & $\begin{array}{c}\text { Reino Unido, } \\
\text { Notthingham } \\
\text { University } \\
\text { Business } \\
\text { School }\end{array}$ \\
\hline $\begin{array}{l}\text { Wheelwe, } \\
\text { Zohar e Hart } \\
(2005)\end{array}$ & $\begin{array}{l}\text { Afirmam a relevância de } \\
\text { oferecimento de } \\
\text { educação sobre } \\
\text { sustentabilidade } \\
\text { ambiental aos atuais } \\
\text { executivos. Relatam a } \\
\text { experiência da } \\
\text { "Sustainable Enterprise } \\
\text { Academy", associação } \\
\text { criada para fomentar a } \\
\text { educação executiva em } \\
\text { sustentabilidade } \\
\text { ambiental. As pesquisas } \\
\text { de satisfação com } \\
\text { estudantes participantes } \\
\text { indicam o sucesso da } \\
\text { iniciativa. }\end{array}$ & Ensino & $\begin{array}{l}\text { Teórico- } \\
\text { Empírica }\end{array}$ & $\begin{array}{l}\text { Quantitativo - } \\
\text { Survey }\end{array}$ & $\begin{array}{c}\text { Canadá, York } \\
\text { University }\end{array}$ \\
\hline $\begin{array}{l}\text { Cornuel } \\
\text { (2007) }\end{array}$ & $\begin{array}{l}\text { Elabora prognóstico } \\
\text { sobre o futuro das } \\
\text { Escolas de } \\
\text { Administração, } \\
\text { destacando seus } \\
\text { principais desafios. } \\
\text { Posiciona a "formação de } \\
\text { líderes globalmente } \\
\text { responsáveis" como um } \\
\text { dos principais desafios e }\end{array}$ & $\begin{array}{l}\text { Ensino/ } \\
\text { Extensão }\end{array}$ & Teórica & Revisão bibliográfica & $\begin{array}{c}\text { Bélgica, } \\
\text { European } \\
\text { Foundation } \\
\text { for } \\
\text { Management } \\
\text { Development }\end{array}$ \\
\hline
\end{tabular}




\begin{tabular}{|c|c|c|c|c|c|}
\hline & $\begin{array}{l}\text { oportunidades das } \\
\text { Escolas de } \\
\text { Administração. A } \\
\text { formação de líderes } \\
\text { globalmente } \\
\text { responsáveis envolve } \\
\text { conhecimento sobre o } \\
\text { ONU Global Compact, o } \\
\text { qual compreende uma } \\
\text { gama de problemas } \\
\text { ambientais a serem } \\
\text { solucionados pela } \\
\text { humanidade. }\end{array}$ & & & & \\
\hline $\begin{array}{l}\text { Walck } \\
(2009)\end{array}$ & $\begin{array}{l}\text { Sistematiza episódios } \\
\text { relevantes do } \\
\text { movimento mundial } \\
\text { para incorporação da } \\
\text { gestão ambiental em } \\
\text { Escolas de Negócios ao } \\
\text { redor do mundo e sobre } \\
\text { o papel dos dirigentes } \\
\text { universitários no desafio } \\
\text { de incluir e apoiar } \\
\text { iniciativas pró-gestão } \\
\text { ambiental nas Escolas de } \\
\text { Administração. }\end{array}$ & $\begin{array}{l}\text { Ensino/ } \\
\text { Extensão }\end{array}$ & Teórica & Revisão bibliográfica & $\begin{array}{c}\text { EUA, Michigan } \\
\text { Technological } \\
\text { University }\end{array}$ \\
\hline $\begin{array}{l}\text { Di Meglio } \\
\text { (2009) }\end{array}$ & $\begin{array}{l}\text { Comenta a tendência de } \\
\text { criação dos chamados } \\
\text { "green Jobs", os } \\
\text { empregos na área de } \\
\text { tecnologias e nichos de } \\
\text { mercado } \\
\text { ambientalmente } \\
\text { inovadores. Segundo a } \\
\text { autora, essas } \\
\text { transformações estão } \\
\text { exigindo que as Escolas } \\
\text { de Negócios e } \\
\text { principalmente os MBAs } \\
\text { incorporem cada vez } \\
\text { mais a temática da } \\
\text { gestão ambiental. }\end{array}$ & $\begin{array}{l}\text { Ensino/ } \\
\text { Extensão }\end{array}$ & Teórica & $\begin{array}{c}\text { Revisão } \\
\text { bibliográfica/Opinião }\end{array}$ & $\mathrm{EUA} / *$ \\
\hline $\begin{array}{l}\text { Peoples } \\
(2009)\end{array}$ & $\begin{array}{l}\text { Apresenta argumentos a } \\
\text { favor da inclusão da } \\
\text { temática ambiental no } \\
\text { ensino de } \\
\text { Administração. } \\
\text { Esquematiza um modelo, } \\
\text { a partir de sua } \\
\text { experiência prática, } \\
\text { sobre como a falta de } \\
\text { capacitação em gestão } \\
\text { ambiental de alguns } \\
\text { administradores pode } \\
\text { sistematicamente } \\
\text { comprometer a inclusão } \\
\text { da preocupação } \\
\text { ambiental nas } \\
\text { organizações. }\end{array}$ & Ensino & Teórica & Revisão bibliográfica & $\begin{array}{c}\text { EUA, } \\
\text { American } \\
\text { Chemical } \\
\text { Society, Green } \\
\text { Chemistry } \\
\text { Institute }\end{array}$ \\
\hline Jabbour & Argumenta sobre a & Ensino/ & Teórica & Revisão bibliográfica & Brasil, \\
\hline
\end{tabular}




\begin{tabular}{|c|c|c|c|c|c|}
\hline (2010) & $\begin{array}{l}\text { relevância as Escolas de } \\
\text { Negócios para a geração, } \\
\text { difusão e incorporação, } \\
\text { pelas próprias Escolas, } \\
\text { de conhecimentos e } \\
\text { práticas de gestão } \\
\text { ambiental. Propõe um } \\
\text { modelo para avaliar o } \\
\text { nível de contribuição das } \\
\text { Escolas de Negócios em } \\
\text { suas atividades } \\
\text { fundamentais: ensino, } \\
\text { pesquisa, extensão e } \\
\text { gestão universitária, } \\
\text { agrupando-as em três } \\
\text { dimensões: criação, } \\
\text { difusão e adoção de } \\
\text { práticas e } \\
\text { conhecimentos sobre } \\
\text { gestão ambiental. }\end{array}$ & $\begin{array}{c}\text { Pesquisa/ } \\
\text { Extensão/ } \\
\text { Administração }\end{array}$ & & & $\begin{array}{c}\text { Universidade } \\
\text { de São Paulo, } \\
\text { Faculdade de } \\
\text { Economia, } \\
\text { Administração } \\
\text { e } \\
\text { Contabilidade } \\
\text { de Ribeirão } \\
\text { Preto } \\
\text { (FEARP). }\end{array}$ \\
\hline $\begin{array}{l}\text { Cremer } \\
(2010)\end{array}$ & $\begin{array}{l}\text { Discorre sobre o papel } \\
\text { das Escolas de Negócios } \\
\text { em países em } \\
\text { desenvolvimento, face os } \\
\text { grandes desafios da } \\
\text { humanidade e das } \\
\text { organizações, dentre } \\
\text { eles, pobreza e meio } \\
\text { ambiente. Afirma que as } \\
\text { Escolas de Negócios dos } \\
\text { países do BRIC (Brasil, } \\
\text { Rússia, Índia e China) } \\
\text { possuem a oportunidade } \\
\text { única de } \\
\text { desenvolvimento de } \\
\text { modelos de ensino de } \\
\text { Administração } \\
\text { diferentes daqueles } \\
\text { adotados em países } \\
\text { desenvolvidos. }\end{array}$ & $\begin{array}{c}\text { Ensino/ } \\
\text { Administração }\end{array}$ & Teórica & Revisão bibliográfica & $\begin{array}{l}\text { China, China- } \\
\text { Europe } \\
\text { International } \\
\text { Business } \\
\text { School }\end{array}$ \\
\hline
\end{tabular}

Observação: o símbolo * representa informação indisponível.

Quadro 2 - Sistematização das principais obras do estado-da-arte do tema.

\section{Perfil do estado-da-arte do tema}

Algumas inferências sobre a produção científica mencionada merecem registro e discussão. A primeira análise diz respeito à nacionalidade e origem de autoria das pesquisas mencionadas, considerando-se as informações relacionadas ao primeiro autor dos artigos com múltiplos autores. Dos 20 artigos aqui considerados, constata-se expressiva concentração de pesquisas provenientes de países considerados desenvolvidos (90\% do total), principalmente dos EUA, responsáveis por $50 \%$ do total da produção apurada. Há apenas duas contribuições de autores vinculados a Escolas de Negócios de países emergentes, no caso China e Brasil, conforme a Figura 3. 


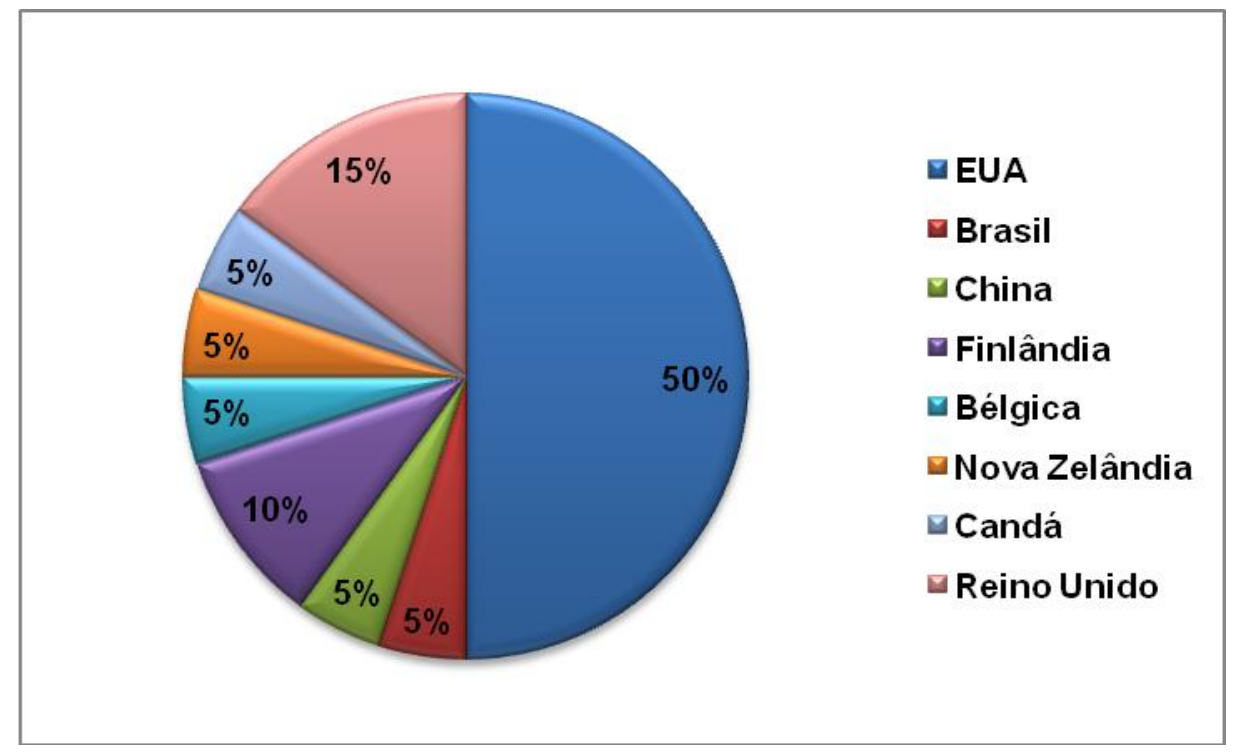

Figura 3 - Distribuição da produção científica analisada com base na nacionalidade da autoria

É relevante notar a forte ênfase dos trabalhos mencionados para apenas uma das atividades essenciais das Escolas de Negócios: o ensino de gestão ambiental, alvo de 13 pesquisas (65\% do total). Cinco pesquisas possuem um foco mais amplo e sistêmico, por considerarem a gestão ambiental nas Escolas de Negócios em mais de uma atividade dessas Escolas (25\% do total). Apenas duas pesquisas (BOYLE, 2004; JABBOUR, 2010) se dedicam à discussão da incorporação da gestão ambiental no conjunto das atividades essenciais das Escolas de Negócios (ensino, pesquisa, extensão e administração), correspondente a apenas a $10 \%$ das pesquisas aqui consideradas. A Figura 4 consolida essas informações.

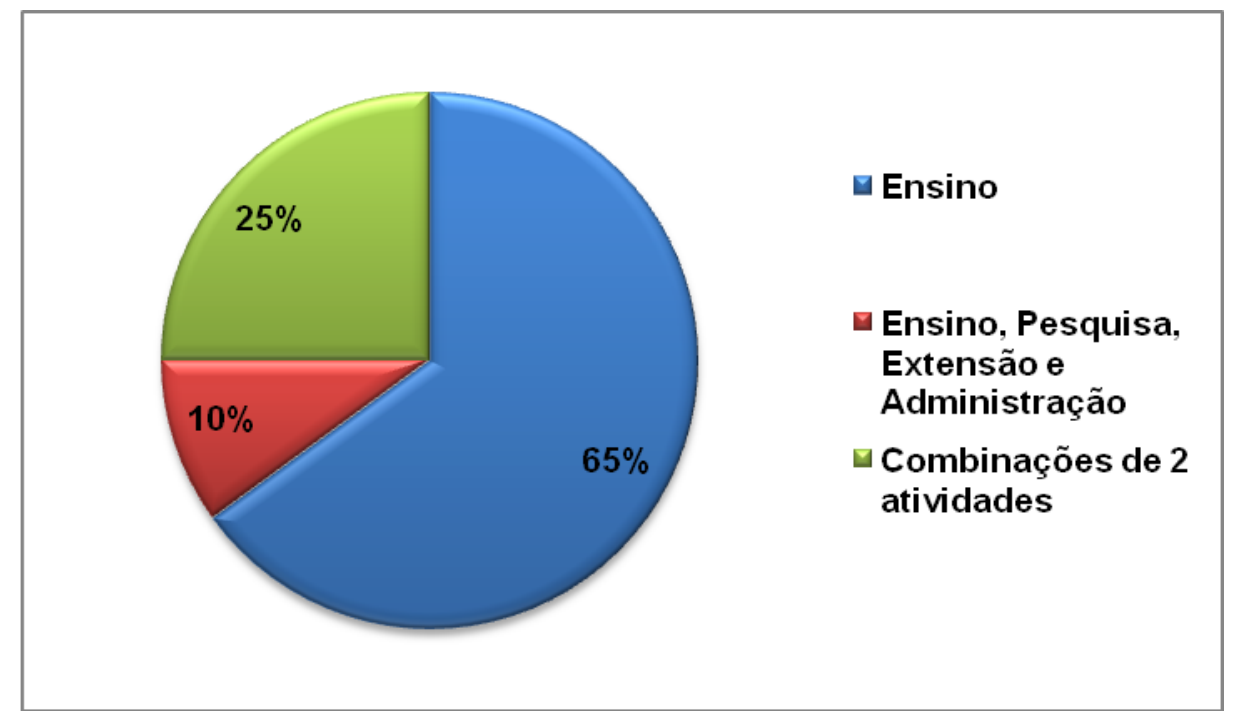

Figura 4 - Distribuição da produção científica analisada com base no nível de abrangência

Do ponto de vista metodológico, constata-se uma forte concentração de pesquisas com perfil teórico, depositadas sobre esforços de revisão e sistematização da literatura existente, adicionando-se, em alguns casos, opiniões e argumentos de seus autores. Essa característica metodológica é dominante e corresponde a $70 \%$ do total (14 pesquisas). De tal forma, seis são as pesquisas analisadas desenvolvidas sob uma perspectiva teórico-empírica: (a) três possuem abordagem quantitativa, baseada em survey, principalmente para verificar a receptividade de alunos de administração à temática ambiental; (b) dois estudos desenvolvem-se sob a égide 
qualitativa, com estratégia de estudo de caso único; e (c) apenas uma pesquisa qualitativa se vale da estratégia de estudo de múltimos casos. Essas constatações podem ser observadas na Figura 5.

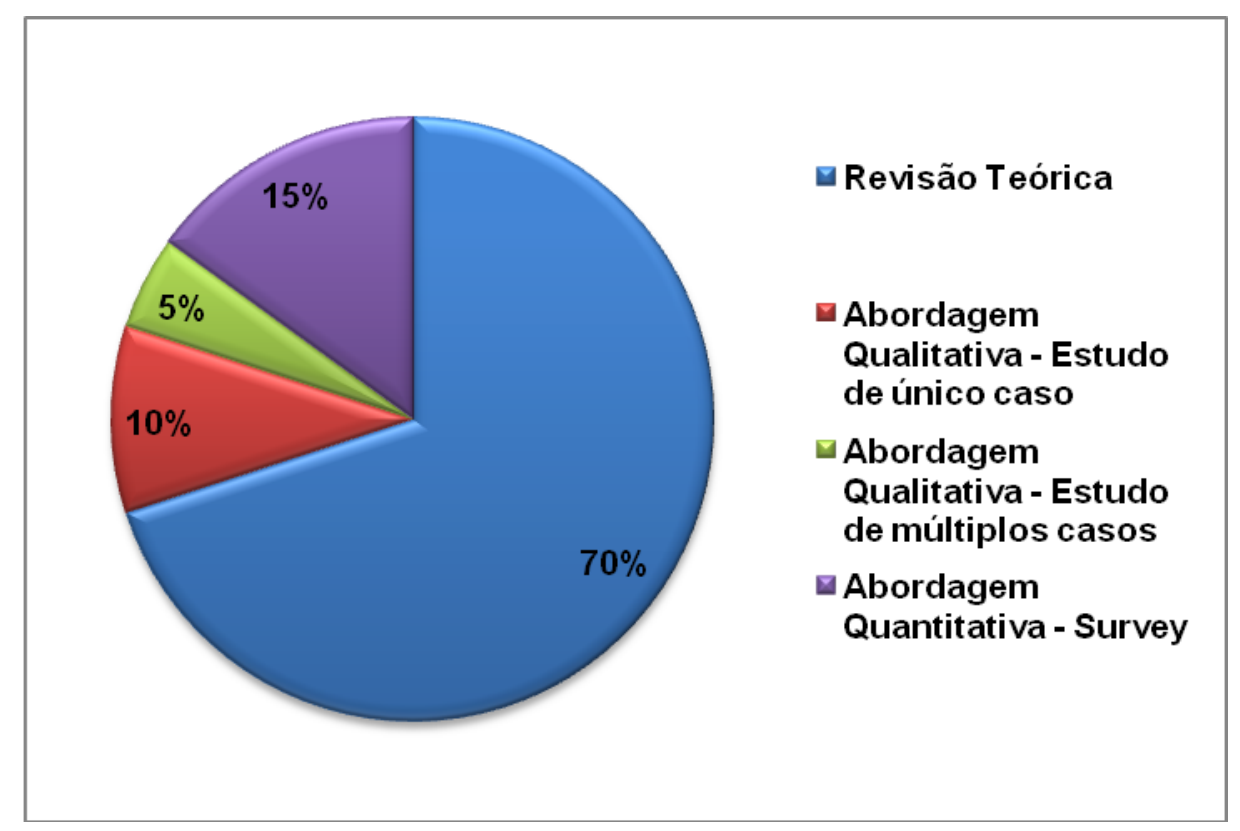

Figura 5 - Distribuição da produção científica analisada segundo seu perfil metodológico do estado-da-arte do tema

Como conseqüência, à luz de uma sistematização da literatura que certamente não é exaustiva, mas sim representativa do estado-da-arte do tema, concluí-se que:

- Há uma pujante liderança de pesquisadores estadunidenses e de outros países desenvolvidos na temática;

- Há um evidente reducionismo analítico das pesquisas, ao enfocarem principalmente a dimensão "ensino", não abordando uma perspectiva sistêmica que englobe a gestão ambiental no conjunto de atividades típicas das Escolas de Negócios;

- Há uma significativa predominância de estudos teóricos sobre o tema e uma conseqüente carência de estudos teórico-empíricos, principalmente de estudo de múltiplos casos.

\section{Conclusões}

Com base no objetivo de pesquisa inicialmente declarado, conclui-se que o campo de pesquisa sobre a incorporação da temática ambiental nas Escolas de Negócios pode ser considerado recente, fragmentado, geograficamente concentrado e metodologicamente limitado:

- Pode ser considerado recente porque o movimento ganhou fôlego e massa crítica no desenrolar da década de 1990, isto é, iniciou-se há cerca de vinte anos (BARNES e FERRY, 1992; HASAN, 1993; SMITH, HART e MCCLOSKEY, 1994; HOFFMAN, 1999);

- Fragmentado porque não foi encontrada pesquisa teórico-empírica que considere a incorporação da gestão ambiental concomitantemente no conjunto das atividades essenciais das Escolas de Negócios - ensino, pesquisa, extensão e gestão universitária. Os relatos de pesquisa sobre gestão ambiental em Escolas de Negócios apresentam-se fracionados, dedicando-se exclusivamente a uma dentre as atividades essenciais mencionadas. A principal dimensão explorada nos relatos de 
pesquisa encontrados é o ensino de administração (por exemplo, GARDINER e LACY, 2005; PEOPLES, 2009);

- A origem institucional dos principais pesquisadores sobre o tema é geograficamente concentrada em países considerados desenvolvidos, como os Estados Unidos da América (RUSINKO, 2005; DI MEGLIO, 2009; PEOPLES, 2009; BOYLE, 2004);

- Metodologicamente limitado em virtude de uma predominância de pesquisas essencialmente depositadas em revisão bibliográfica ou proposição conceitual, com raros exemplos de pesquisas teórico-empíricas (HASAN, 1993; SMITH, HART e MCCLOSKEY, 1994; KEARINS e SPRINGETT, 2003).

A Figura 6 compreende uma ampla gama de temas que podem ser úteis para o avanço do estado-da-arte da incorporação da gestão ambiental nas atividades essenciais de Escolas de Negócios.

Esses temas envolvem, por exemplo, a necessidade de novos esquemas para a classificação das Escolas em estágios evolutivos ambientais, a identificação e difusão de melhores práticas, a investigação dos efeitos da inclusão da gestão ambiental na reputação das Escolas de Negócios, bem como os desafios e benefícios desse processo e a influência de aspectos culturais no greening das Escolas de Negócios.

Os temas sugeridos podem ser investigados dentro de diversas perspectivas, desde aquelas focadas na Escola de Negócios, até perspectivas mais amplas, que consideram Escolas de Negócios internacionais. Pode-se também investigar o fenômeno dentro da Universidade em que a Escola de Negócios atua ou compará-la com a realidade de Escolas da região.

Diferentes abordagens metodológicas podem apoiar esse processo de investigação. Abordagens mais robustas são preferíveis, pois combinam tanto procedimentos metodológicos qualitativos como quantitativos, mas há oportunidades de pesquisa em todos os temas propostos dentro de uma perspectiva também exclusivamente qualitativa ou exclusivamente quantitativa.

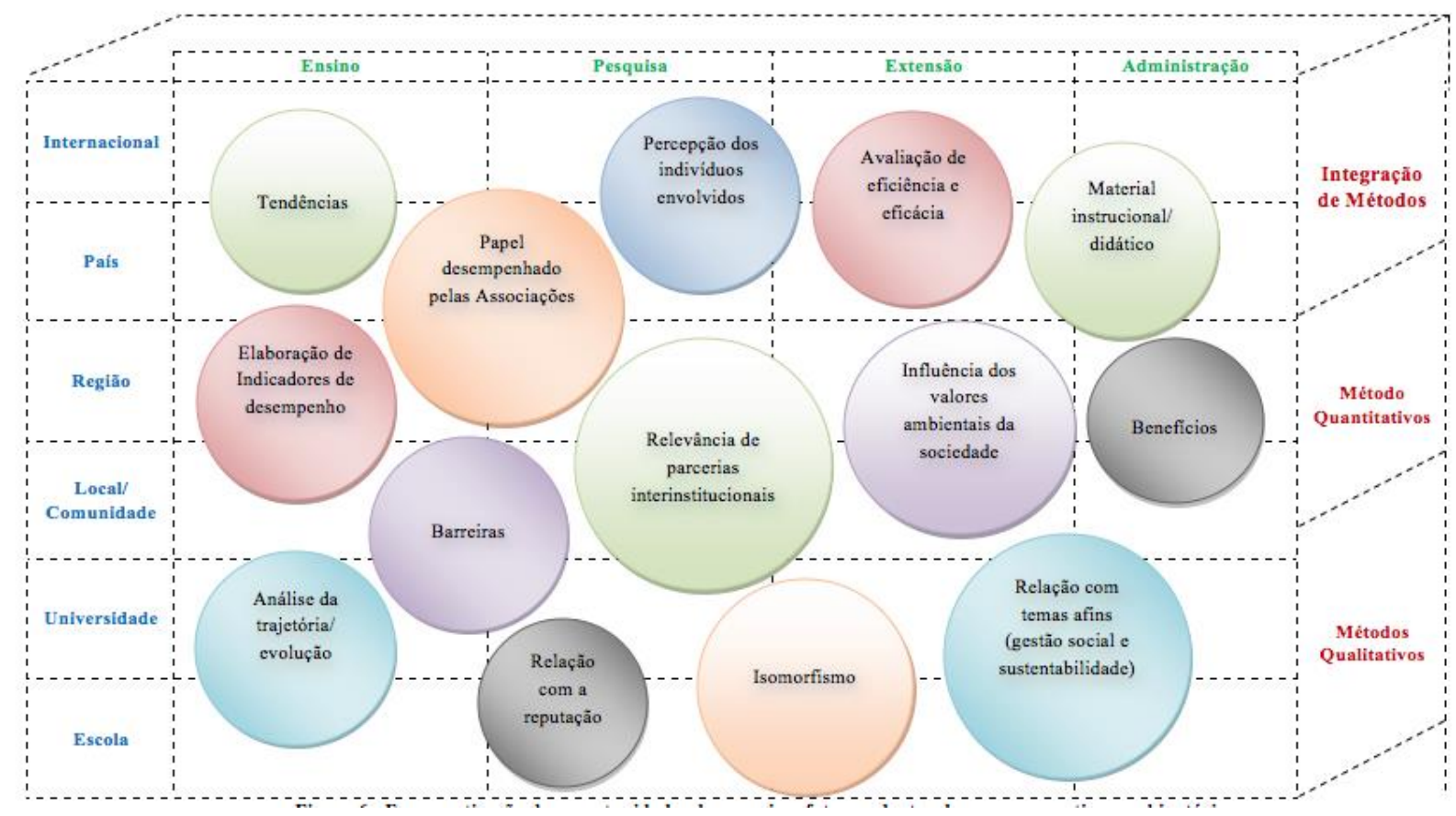

Figura 6 - Esquematização das oportunidades de pesquisas futuras, dentro de uma perspectiva combinatória. 


\section{Referências}

AOM. Academy of Management Annual Meeting 2009 - Green Management Matters, Academy of Management, Chicago, IL, available at: http://meeting.aomonline.org/2009 (accessed September 2009).

BARNES, J.A.; FERRY, J.K. Creating a niche for the Environment in the Business School curriculum. Business Horizons, March-April, p.3-8, 1992.

BOIRAL, O. Global warming: should companies adopt a proactive strategy? Long Range Planning, Vol. 39, p. 315-330, 2006.

BOYLE, M. Walking our talk: Business Schools, legitimacy and Citizenship. Business \& Society, Vol.43, p.37-68, 2004.

COHEN, J.A. Teaching environment to the B-Schools. Management Review, 30-34, 1990.

COOPEY, J. Sustainable development and environmental management: the performance of UK business schools. Management Learning, Vol.34, N.1, p.5-26, 2003.

CORDANO, M.; ELLIS, K.M.; SCHERER, R.F. Natural capitalists: increasing business students' environmental sensitivity. Journal of Management Education, Vol.27, N.2, p.144-157, 2003.

CORNUEL, E. Challenges facing Business Schools in the future. Journal of Management Development, Vol.26, N.1, p.87-92, 2007.

CREMER, R.D. Chinese business schools and the future of management in the post-crisis era. Chinese Management Studies, Vol.4, N.1, p.11-17, 2010.

CROWE, D. BRENNAN, L. Environmental considerations within manufacturing strategy: an international study. Business Strategy and The Environment, Vol.16, p.266-289, 2007

DARNALL, N, HENRIQUES, I, SADORSKY, P, Do environmental management systems improve business performance in an international setting? Journal of International Management, Vol.14, N.4, p.364-376, 2008

DI MEGLIO, F. MBA Programs go green. Bloomberg Businessweek, January, 2009.

EGRI, C.P.; ROGERS, K.S. Teaching About The Natural Environment In Management Education: New Directions And Approaches. Journal of Management Education, vol. 27 no. 2 139-143, 2003

FORRAY, J.M.; LEIGH, J. Special Issue on Principles of a Responsible Management Education (PRME) - Call for Papers. Journal of Management Education, Vol.33, N.5, p.647-648, 2009.

GARDINER, L.; LACY, P. Lead, respond, partner or ignore: the role of Business Schools on corporate responsibility. Corporate Governance, Vol.5, N.2, p.174-185, 2005.

GONZALEZ-BENITO, J.; GONZALEZ-BENITO, O. Environmental proactivity and business performance: an empirical analysis. Omega, Vol. 33, N.1, p.1-15, 2005.

Hasan, J.S.M. The greening of Business Schools. Journal of Teaching in International Business, Vol.5, N.1/2, p.9-18, 1993.

HOFFMAN, A.J. Environmental education in Business Schools. Environment, January/February, p.1-2, 1999. 
IRALDO, F.; TESTA, F.; FREY, M. Is an environmental management system able to influence environmental and competitive performance? The case of the eco-management and audit scheme (EMAS) in the European Union, Journal of Cleaner Production, Vol.17, N.16, p.1444-1452, 2009.

JABBOUR, C.J.C. Greening of Business Schools: a systemic view. International Journal of Sustainability in Higher Education, Vol.11, N.1, p.49-60, 2010.

JACOBS, B.W., SINGHAL, V.R., SUBRAMANIAN, R, An empirical investigation of environmental performance and the market value of the firm. Journal of Operations Management, Vol. 28, N.5, p.430-441, 2010.

JAKOBSEN, O.D., IMS, K.J., GRONHAUG, K. Faculty members' attitudes toward ethics at Norwegian Business Schools: an exploratory study. Journal of Business Ethics, Vol. 62, p. 299-314, 2005.

KEARINS, K.; SPRINGETT, D. Educating for sustainability: developing critical skills. Journal of Management Education, Vol.27, p.188-204, 2003.

MOLINA-AZORIN, J.F., CLAVER-CORTÉS, E., LÓPEZ-GAMERO, M.D., TARÍ, J.J.. Green management and financial performance: a literature review. Management Decision, Vol. 47, N. 7, p.1080-1100, 2009.

ONZOÑO, S.I.; CARMONA, S. The changing business model of B-Schools. Journal of Management Development, Vol.26, N.1, p.22-32, 2007.

PEOPLES, R. Preparing today for a sustainable future. Journal of Management Education, Vol.33, N.3, p.376-383.

PESONEN, H. Challenges of integrating environmental sustainability issues into Business Schools Curriculum: a case study from The University of Jyväskylä, Finland. Journal of Management Education, Vol.27, N.2, p.158-171, 2003.

PRME-ONU. PRME - Principles for a Responsible Management Education, United Nations. Available at: http://www.unprme.org/, (accessed January 2010).

ROHWEDER, L. Integrating environmental education into Business Schools' educational plans in Finland. GeoJournal, Vol.60, p.175-181, 2004.

RUSINKO, C.A.; SAMA, L.K. Call for Papers: Special Issue: Greening Across the Management Curriculum. Journal of Management Education, Vol.30, N.626-627, 2006.

SARKIS, J., GONZALEZ-TORRE, P., ADENSO-DIAZ, B. Stakeholder pressure and the adoption of environmental practices: the mediating effect of training. Journal of Operations Management, Vol. 28, p.163-176, 2010.

SCHWARTZ, R.H., KASSEM, S., LUDWIG, D. The role of Business Schools in managing the incongruence between doing what is right and doing what it takes to get ahead. Journal of Business Ethics, Vol.10, p.465-469, 1991.

SMITH, D.; HART, D.; MCCLOSKEY, J. Greening the business school. Management Learning, Vol.25, N.3, p.475-488, 1994.

SOUTHWICK, T.P. Westinghouse's Environmental School: combining Business with Ecology. Science, Vol.169, p.453-454, 1970. 
SROUFE, R. Effects of environmental management systems on environmental management practices and operations. Production and Operations Management, Vol.12, N.3, 416-430, 2003.

STARIK, M.; RANDS, G.; MARCUS, A.A.; CLARK, T. Call for Papers, The Academy of Management Learning \& Education, Special Issue on Sustainability in Management Education, Academy of Management Learning \& Education, 2010.

STARKEY, K.; TIRATSOO, N. The Business Schools and the Bottom Line. Cambridge University Press, United Kingdom, 2007.

SWANSON, D.L. The bucks stops here: Why universities must reclaim business ethics education. Journal of Academic Ethics, Vol.2, p.43-61, 2004.

THOMAS, H.; LI, X. Mapping globally branded Business Schools: a strategic positioning analysis. Management Decision, Vol.47, N.9, p.1420-1440, 2009.

THOMPSON, G.P. The environment movement goes to business school, Environment, Vol. 27, p. 7 , 1985.

VACHON S, KLASSEN, R.D. Environmental management and manufacturing performance: The role of collaboration in the supply chain. International Journal of Production Economics, Vol.111, N.2, p.299-315, 2008

WALCK, C. Integrating sustainability into management education: a dean's perspective. Journal of Management Education, Vol.33, N.3, p.384-390, 2009.

WHEELER, D.; ZOHAR, A.; HART, S. Educating senior executives in a novel strategic paradigm: early experiences of the Sustainable Enterprise Academy. Business Strategy and the Environment, Vol.14, p.172-185, 2005.

WOOLVERTON, A., DIMITRI, C. Green marketing: are environmental and social objectives compatible with profit maximization? Renewable Agriculture and Food Systems, 25, 2, p.90-98, 2010.

YANG, C.; LIN, S., CHAN, Y., SHEU, C. Mediated effect of environmental management on manufacturing competitiveness: an empirical study. International Journal of Production Economics, 123, p.210-220, 2010. 